\title{
دراسة تحليلية لسلسلة توريد الالبان ومنتجاتها
}

\section{إبراهيم صديق علي ، أسماء أبومسلم عبد الخالق أبومسلم}

قسم الاقتصاد الزراعي - كلية الزراعة - جامعة المنوفية

Received: Jul. 16, 2017

Accepted: Jul. 25,2017

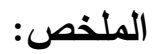

تعد الثروة الحيوانية إحدى الركائز الأساسية للإنتاج الزراعي في مصر، حيث تعد عاملا هاما من عوامل الاستقرار

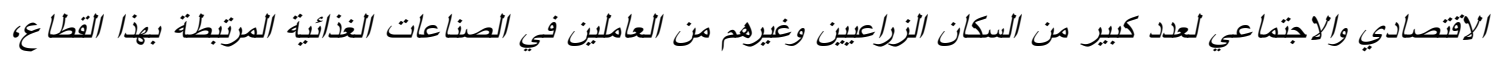

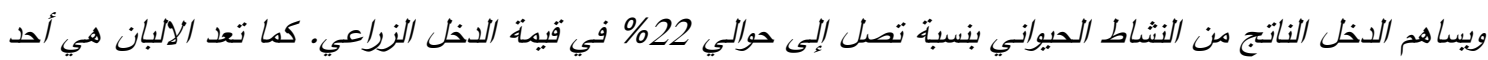

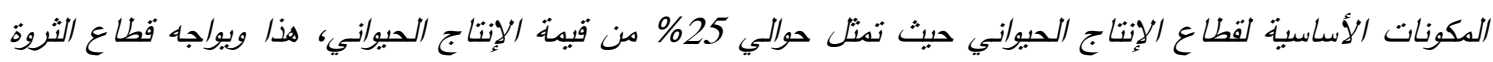

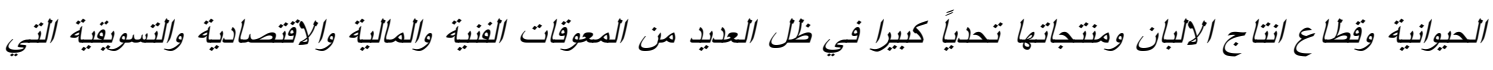

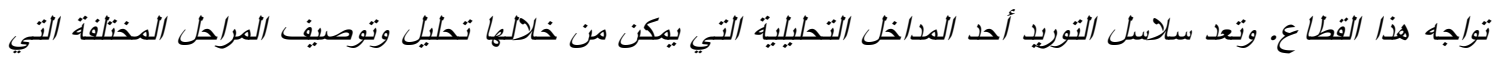
تمر بها هذه الدنتجات. وبتحليل سلسلة توريد الالبان ومنتجاتها ومن خلال التحلبل البيئي الرباعي أمكن تحديد أهم الدشاكل والدعوقات

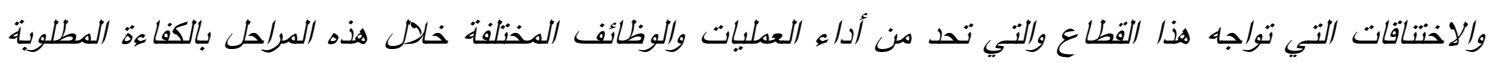
والمتمثلة في ارتفاع وتقلب أسعار العناصر والمستلزمات والخدمات الإنتاجية والتصنيعية، وضعف التان العلاقات التات التكاملية وانعدام

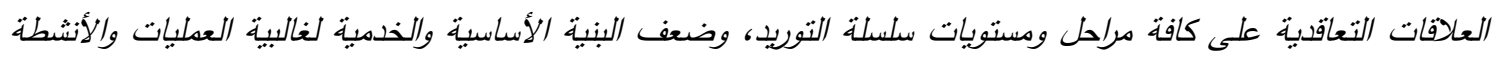

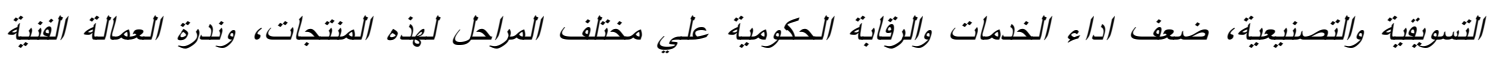

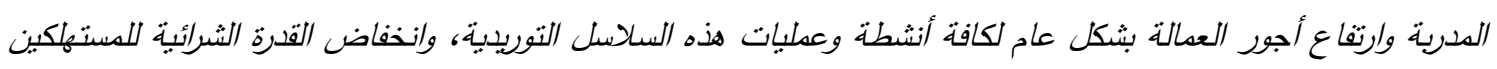
في الأسواق المحلية.

هذا وقد تم اقتراح بعض السياسات والحلول التي من شأنها النهوض بهذا القطاع وقد تمثل أههها في إعادة هيكلة الجمعيات التعاونية للمنتجبن والدصنعين وخطوط الأتنمان واستعادة دورها في تدعيم كافة مستلزمات الإنتاج وتوفير التمويل

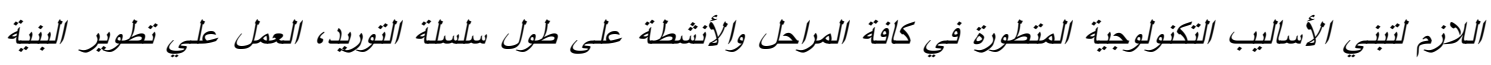

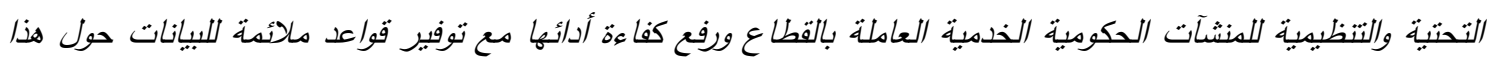

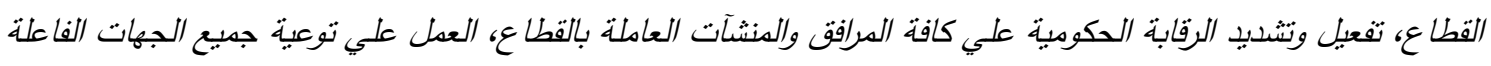

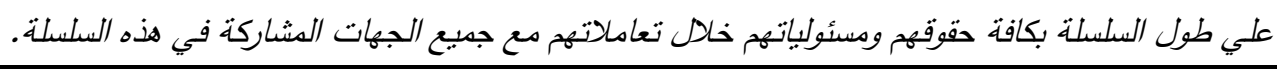

مساهمة قيمة الدخل الناتج من النشاط الحيواني في الدخل الزراعي لتصل إلى حوالي 22\% من قيمة الدخل الزراعي

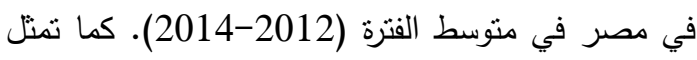
قيمة الالبان حوالي 25\% من فيمة فئ الإنتاج الحيواني لنفس

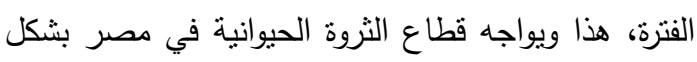

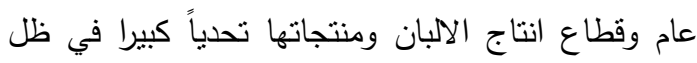
العديد من المعوقات الفنية والمالية والاقتصادية والتسويقية

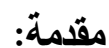

تعد الثروة الحيوانية إحدى الركائز الأساسية للإنتاج

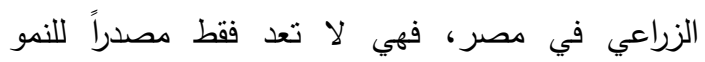

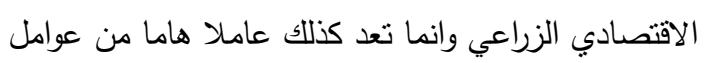

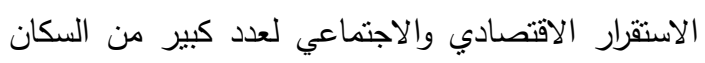
الزراعيين وغيرهم من العاملين في قطاع الإنتاج الحيواني

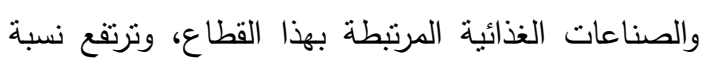




\section{S. Ali and Asmaa A. A. Abou-Mosalam}

والأنشطة داخل القطاع، وأهم الفرص والتهديدات. وإككانية التوصل إلى مجموعة من السياسات والحلول التي من داني شأنها تعزيز نقاط القوة ومعالجة نقاط الضعف والاستفادة من الفرص والتقليل من أثز التهديدات ومن ثم إمكانية النهوض بقطاع الالبان ومنتجاتها في مصر.

\section{البيانات والطريقة البحثية:}

اعتمدت الدراسة في تحقيق أهدافها على البيانات الثانوية المنشورة وغير المنشورة بمطبوعات وقواعد البيانات على الثبكة الدولية وسجلات كلا من وزارة الزراعة، والجهاز المركزي للتعبئة العامة والإحصاء، والهيئة العامة للطب البيطري. كما اقتضت الدراسة اجراء العديد من والنهاهن المقابلات مع الجهات الفاعلة في المراحل المختلفة لسلسلة توريد الالبان ومنتجاتها للحصول على البيانات الأولية بجمع عينة عشوائية بسيطة تضم كل من منتجي الالبان ومجمعي الالبان ومعامل ومصانع منتجات الالبان خلال العام 2016/2015. هذا بالإضافة إلى القيام ببعض ولإن القان المقابلات مع بعض المسئولين عن الإنتاج الحيواني. وقد

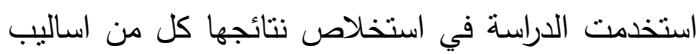
التحليل الإحصائية الوصفية والكمية، بالإضافة الي استخدام أسلوب التحليل البيئي الرباعي للوقوف علي أهم نقاط القوة ونقاط الضعف والفرص والتهديدات.

\section{أولاً: سلسلة توريد 1 الألبان ومنتجاتها}

تثبر سلسلة توريد الألبان ومنتجاتها إلى كافة الأنشطة

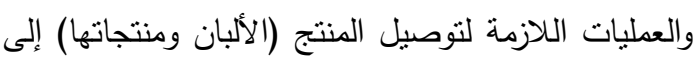
المستهلكين النهائين مرورا بالمراحل المختلفة حيث تمر لهرئ الالبان ومنتجاتها بالعديد من المراحل والعمليات بداية من توريد العناصر والمدخلات الإنتاجية ومرورا بالمراحل الإنتاجية والتصنيعية والنتويعية وحتى وصول الكنتجات النهائية الي المستهلاك النهائي. وتتشتمل سلسلة نوريد الألبان ومنتجاتها على العديد من المنتجات حيث تشنمل على الألبان الطازجة والمنتجات الثقليدية للألبان (الزبد

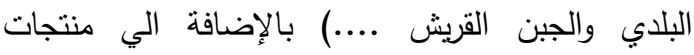

\footnotetext{
${ }^{1}$ - Supply Chain
}

التي تواجه هذا القطاع، حيث بعاني من العديد من المشكلات خلال مراحله المختلفة بداية من توريد العناصر والمدخلات الإنتاجية ومرورا بالمرحل المختلفة الإنتاجية

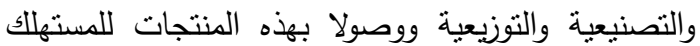
النهائي. وتعد سلاسل التوريد أحد الدداخل التحليلية التي يمكن من خلالها تتبع المنتجات خلال مراحلها المختلفة للتعرف على أهم المشاكل والمعوقات والاختناقات التي نواجهها والتي تحد من أداء العمليات والوظائف المختلفة خلال هذه المراحل بالكفاءة المطلوبة، ومن ثم إمكانية التوصل إلى الى

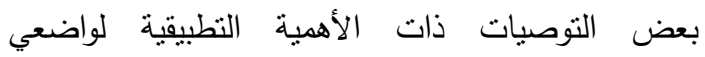
السياسات الزراعية المصرية والتي من شأنها العطل على الهي رفع الكفاءة الإنتاجية لهذا القطاع على طول مراحله

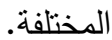

مشكلة الدراسة: على الرغم من قطاع الالبان ومنتجاتها، لما يساهم به في قيمة الدخل الحيواني ومن ثم الدخل الزراعي والقومي وما يقدمه من فرص عمل، إلا انه يواجه بالعديد من المشكلات خلا المراحل المختلفة التي تمر بها منتجاته. ومن ثم تبرز أهمية دراسة هذه المراحل المختلفة التي تمر بها الالبان ومنتجاتها للتعرف على أهم المشاكل والاختناقات التي تواجهها والتي تحد من أداء العمليات والوظائف التهات المختلفة خلال هذه المراحل بالكفاءة المطلوبة.

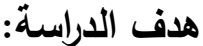

تعد دراسة المراحل المختلفة التي تمر بها الالبان ومنتجاتها من خلال وصف جميع هذه المراحل والعمليات والخدمات الأساسية التي تتم على طول هذه السلسلة ابتداء من المنتجين ووصولا بالسلع النهائية للمستهلكين، والتعرف لهان

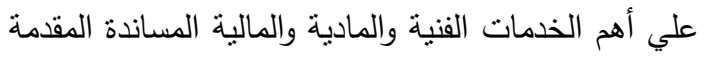
لهذا القطاع هو الهدف الرئيسي من إجراء التحليل لسلسلة نوريد الالبان ومنتجاتها، ومن ثم امكانية تحديد أهم نقاط القوة الني يتمتع بها هذا القطاع، وكذللك نقاط الضعف والمشاكل والاختناقات الني تعترض أداء العمليات 


\section{An Analysis Study of Dairy and Dairy Products Supply Chain}

كحيوانات منتجة للبن بنحو 22.2\%، اما باقي المربين والبالغة نسبتهم 29.6\% فيقومون بتربية كل من الابقار والجاموس معا. ويحصل المنتجون على الحيوانات المنتجة للبن من العيد من المصادر الهنتئة في: أسواق الحيوانات الحية (70\%)، نتاج المزرعة من الاناث والتي يتم ترييتها داخل المزرعة حتى نخخل في العطلية الإنتاجية (22.2\%)، الاسنتراد حيث

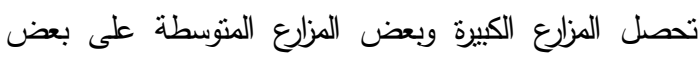

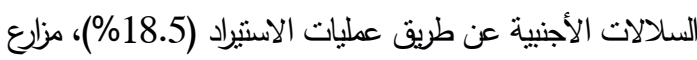
الثركات التتخصة حيث تحصل بعض المزارع الصغيرة والمتوسطة على بعض الابقار الخليطة من الحيوانات التي ينم الاستخناء عنها من مزارع الثركات الكيبرة (11\%).

الأعلاه: تحد الأعلاف الخضراء الهصر الرئيسي لتخنية حيوانات

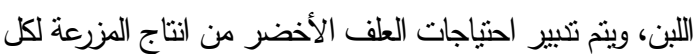

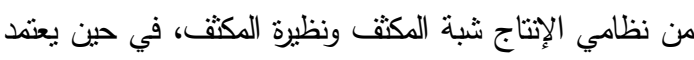

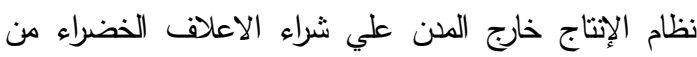
المزارعين لتنيير احتياجات المزرعة من الاعلاف الخضراء. ويتركز استخدام السيلاج في تغنية حيوانات اللبن في كل من نظامي

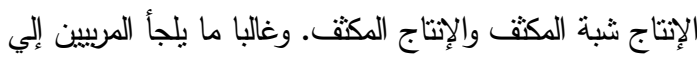

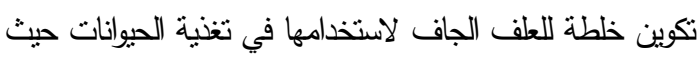

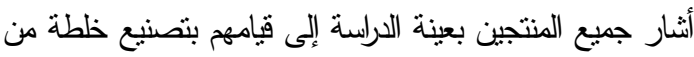
الاعلاف الجافة داخل مزارعهم ونلك لعدة أسباب تندل أهمها في: أ. انخفاض تكلفة خلطة العلف المنتج بالمزرعة مقارنة

$$
\text { بالأعلاف الجاهزة (100\%). }
$$

ب. عدم الثقة في جودة الاعلاف الجاهزة وفي محتواها العناصر الغذائية، وفيما تحققه من نتائج (74\%).

العمالة: يزداد الطلب على العمالة المدربة وخاصة المستخدمة في عملية الحلابة في المزارع متوسطة الحجم والتي تمثل الركيزة الأساسية في عمل هذه الهية في المزارع. في

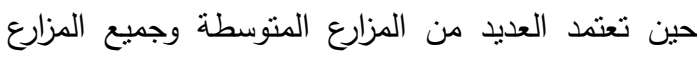
الكبيزة على عنصر العمل الالي بدلا من العمل البشري

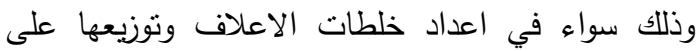

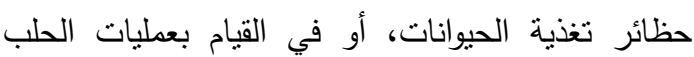
باستخدام المحالب الالية أو النصف الية. وقد بلغت نسبة لفية

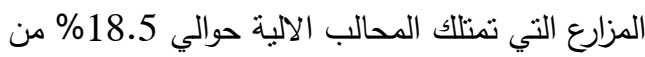

المعامل البلدية من الجبن الأبيض والاسطنبولي والجبن الرومي وكذلك منتجات الشركات الحديثة من الألبان المبسترة والزبادي والجبن المعلب وغيرها من المنتجات المصنعة للألبان، بالإضافة الي منتجات الألبان المستوردة من الخارج. هذا وتضم هذه السلسلة العديد من الجهات الفاعلة المتمثلة في المنتجين الأوليين ومجمعي الألبان والدصنعين وتجار الجملة والتجزئة والدستهلكين. وتتم هذه العمليات والأنشطة على طول سلسلة التوريد من خلال مجموعة متكاملة من الخدمات والأنشطة المباشرة ونظيرتها المساندة والتي تساهم في إنجاح وتعزيز قدرات هذه العطليات والأثشطة. كما تختلف مراحل وأنشطة وعمليات

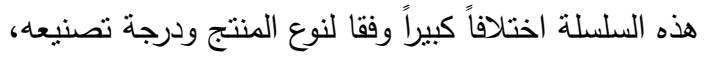
ويمكن التعرف على المراحل المختلفة التي تمر بها الألبان

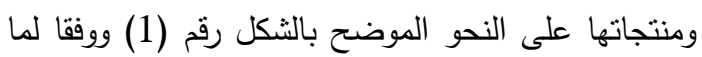
يلي:

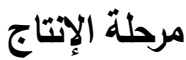
تتم عملية انتاج الألبان من خلال قيام منتجي الألبان بتربية حيوانات اللبن بسلالاتها المختلفة وتوفير مستلزمات وخدات الإنتاج اللازمة للاخول في العملية الإنتاجية والحصول على الناتج (الألبان) من هذه العطلية الإنتاجية. هذا وتتمتل أهم هذه العناصر والمستلزمات الإنتاجية في كل من الحيوانات المنتجة للبن والاعلاف والعمالة، لإهات بالإضافة إلى الخدمات الإنتاجية الحكومية والتي تشاند العملية الإنتاجية والمنتكة في الخدمات البيطرية وخدمة التأمين على المانشية وخدمات الايتمان والتمويل وخدمات

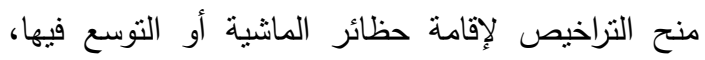
والتي سيتم تناولها بالتفصيل في الجزء التالي:

الحيواتات المنتجة للبن: تختلف أنواع وسلالات الحيوانات

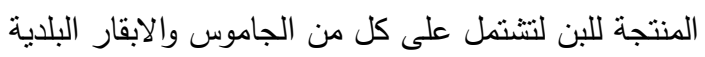
والخليط والأجنبية، وقد بلغت نسبة القائمين بإنتاج اللبن

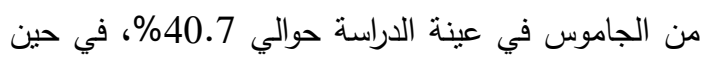
بلغت نسبة الحائزين للأبقار الخليطة لإنتاج اللبن حوالي

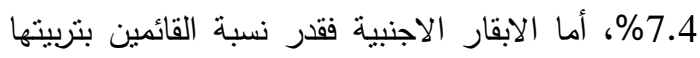




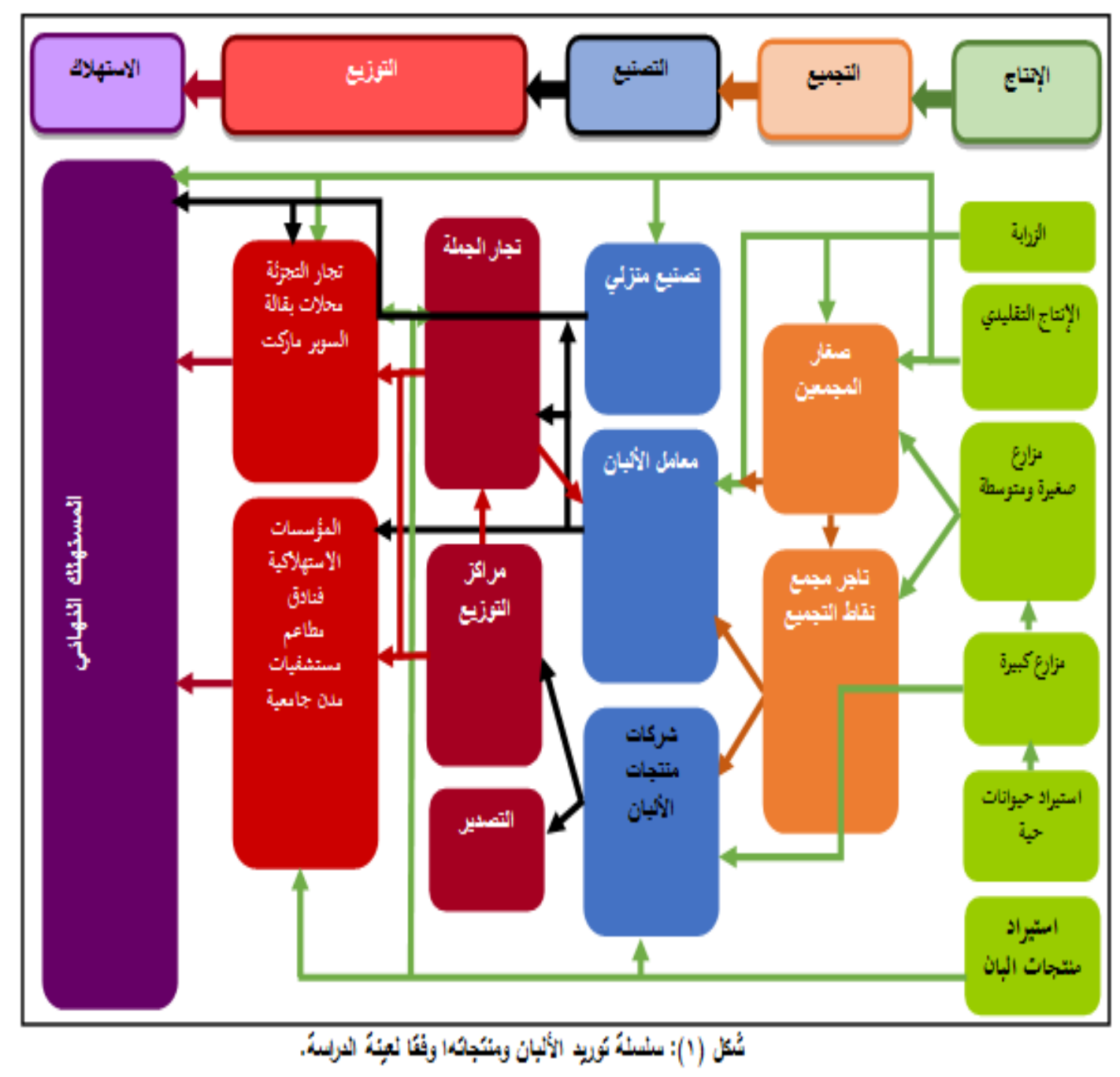




\section{An Analysis Study of Dairy and Dairy Products Supply Chain}

الزراعي بفائدة بنكية تراوحت بين 15\%-18\%، مقارنة بالفائدة البنكية من البنوك التجارية الأخرى الني قدرث

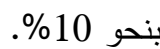

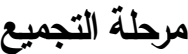

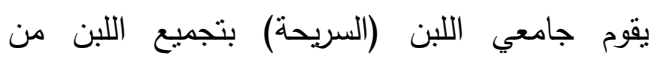
المنتجين وتوصيلة للحلقة التالية في سلسلة التوريد. حيث يتعامل مجمعين الألبان على اختلاف حجم تعاملاتهم مع لعاله

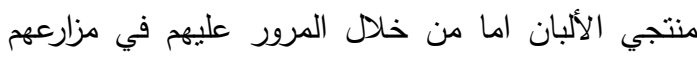
باستخدام التروسيكل، او عن طريق قيام المنتجين أنفسهم بتوصيل الألبان الي المجمعين في مراكز التجميع الخاصة التران بهم (85.7\%)، كما قد يلجا المجمع لاتباع كلا الطريقتين

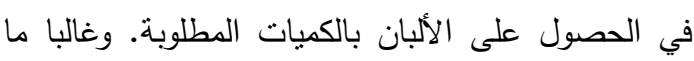

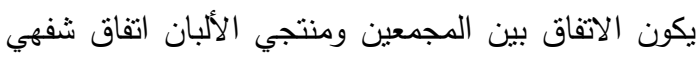

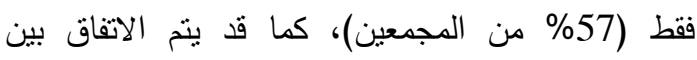
المجمع وبعض المنتجين من خلال دفع مبلغ مالي مقدم

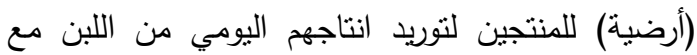
تحديد سعر مبدئي يتم التعامل به وكذلك بعض مواصفات اللبن الخاصة بنسبة الدهن ونسبة حموضة اللبن وذلك بجانب الاتفاقات الثفهية (43\% من المجمعين). وغالبا ما يتم التعامل بين المجمعين ومنتجي الألبان بشكل آجل على أن يتم نصفية الحساب بين الطرفين في نهاية كل

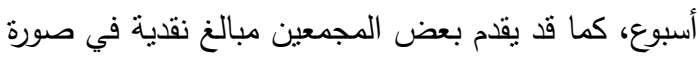
سلف لبعض صغار المنتجين ويتم بموجبها نوريد الألبان حتى انتهاء قيمة هذه السلف. ويقوم هؤلاء المجمعين بتوريد اللبن المجمع لديهم الي

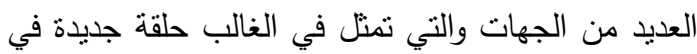

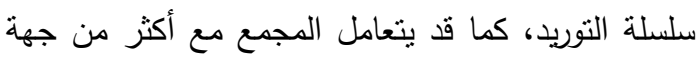
في نفس الوقت وذلك وفقا لكمية اللبن المجمعة لديه، وتشمل هذه الجهات على معامل الألبان: حيث بلغت نسبة

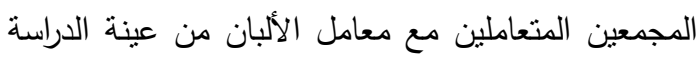
حوالي 71.4\%. تاجر جملة: حيث يقوم مجمعي الألبان بتوصيل وتسليم الألبان المجمعة لديهم لتاجر جملة للألبان والذي ينعامل في كميات أكبر من اللبن ومع عدد من

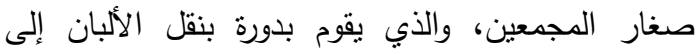

المزارع بعينة الدراسة بالإضافة الي امتلالك مزرعة واحدة لمحلب نصف الي، في حين تعتمد باقي المزارع في عينة الدراسة على العمال في عملية الحلابة (الحلب اليدوي). الخمات البيطرية: غالبا ما يعتمد صغار المنتجين والقليل من المزارع المتوسطة على الخدمات البيطرية المقدة من جانب الوحدات البيطرية التابعة للهيئة العامة للذدمات البيطرية والمتواجدة في القري الرئيسية، في حين تعتمد البيد غالبية المزارع المنوسطة والكبيرة على الخدمات البيطرية الخاصة وذلك من خلال التعاقد مع بعض الأطباء البيطريين للقيام بعمليات المتابعة والرعاية والعلاج، كما يتم

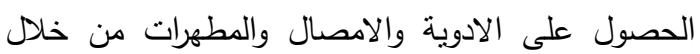

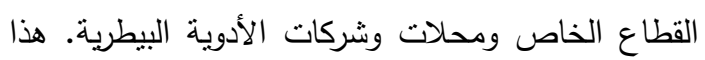
ولم يعتمد أي من المنتجين في عينة الدراسة على الخدمات البيطرية المقدمة من جانب القطاع الحكومي بشكل منفرد، حيث أثنار حوالي 44.4\% منهم إلى اعتمادهم على البى الخدمات البيطرية المقدمة من القطاع الخاص بجانب تلك الكالك

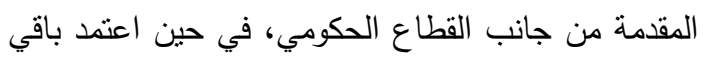
المبحوثين أي حوالي 55.6\% على الخدمات البيطرية المقدمة من القطاع الخاص فقط.

منح التراخيص اللازمة لإقامة الحظائر: أثنار حوالي 44.4\%

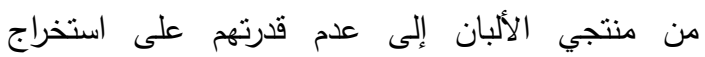
التراخيص اللازمة لإقامة الحظائر أو التوسع فئه فئها، بالإضافة إلى التعرض لمخاطر عمليات الازالة للمنشآت

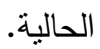

التأمين على الحيوانات: أثنار المنتجين إلى الغاء نظام التأمين على الحيوانات الذي كان يتم نطبيقه سابقا وما

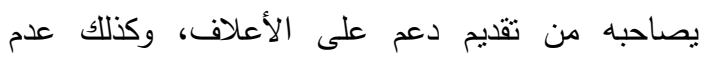

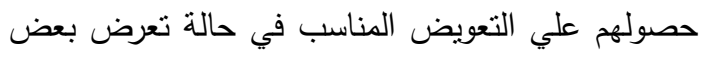
الحيوانات للنفوق.

الاتثمان والتمويل: تبين قيام 22.2\% من عينة منتجي الألبان بالحصول على قروض للاخول في النشاط الإنتاجي أو للتوسع به، وقد حصل حوالي 50\% من هؤلاء المنتجين على القروض من بنك التتمية والائتمان 


\section{S. Ali and Asmaa A. A. Abou-Mosalam}

من منتجي الألبان في المناطق المحيطة بالمعامل

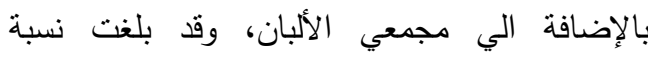
المعامل التي تحصل على جزء من احتياجاتها من الألبان من المنتجين بشكل مباشر حوالي 50\% من

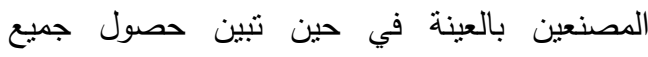

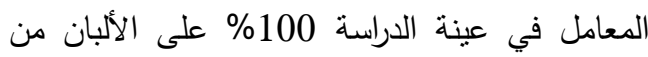

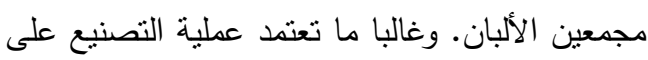
أساليب تكنولوجية غير منطورة حيث يكون العامل البشري (العمالة الفنية الماهرة) هو الأساس في العملية

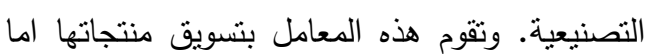
من خلال منفذ بيع خاص بها، أو من خلال القيام

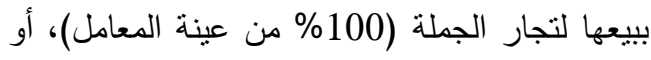

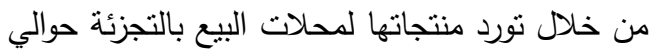

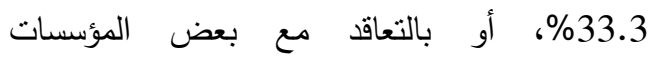

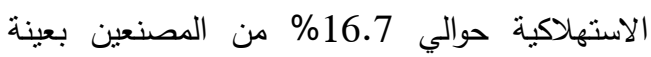
الدراسة وذلك بجانب التوريد لتجار الجملة. ويكون الاتفاق بين أصحاب هذه المعامل والمتعاملين معهم في سواء في توريد الالبان الخام أو في المرحلة النالية بشكل شفوي وبدون تعاقدات رسمية.

شركات منتجات الألبان²: تحصل مصانع شركات

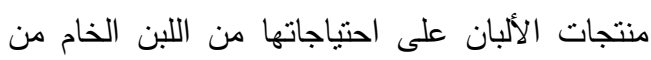

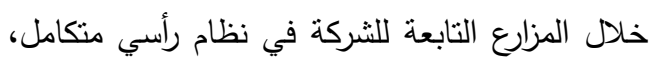

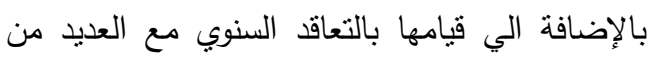

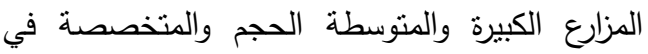

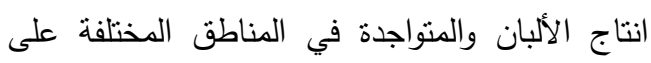

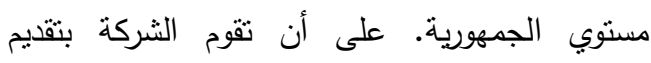
مجموعة من الخدمات لهذه المزارع التي يتم التعاقد

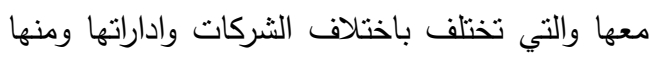
توفير تتكات تبريد للمزارع لتخزين اللبن حتى بنى بنت توريده-القيام بعمل دورات تدريبية لأصحاب المزارع تلبرن لتحسين خبراتهم من خلال بعض الخبراء-مساعدة أصحاب المزارع علي القيام باستيراد عجلات اجنبية-

2- تم الحصول على هذه المعلومات من خلال مقابلة مع المهندس صفوان ثابت مدير شركة جهينة للألبان ومنتجاتها.
الحلقة التالية في السلسلة (43\% من عينة مجمعي الألبان). منفف بيع خاص بالمجمع: حيث يقوم بعض فئل

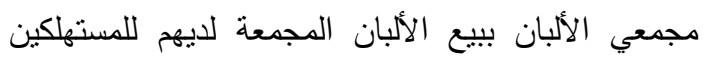

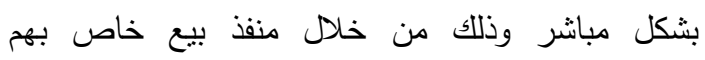

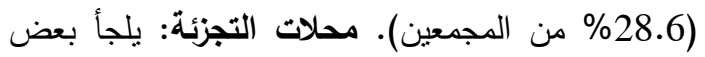

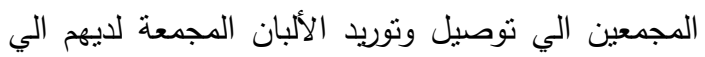
بعض المحلات التجارية والسوبر ماركت ومحلات منتجات الألبان المتواجدة في العديد من القري والمدن، (14.3\%).

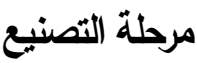

يمكن تعريف هذه المرحلة على أنها المرحلة التي يتم فيها تحويل اللبن من صورته الخام الي منتجات نهائية تامة الصنع، وتختلف هذه المنتجات وفقا لطبيعة العملية التصنيعية والقائم بهذه العملية حيث بمكن التفرقة بين ثلاثة طرق تصنيعية خلال هذه المرحلة وتنوقف هذه

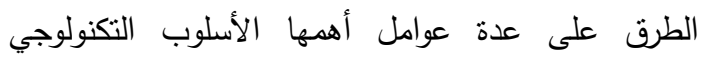
المستخدم في العملية التصنيعية والطاقة الإنتاجية ونوعية المنتجات المصنعة وتتتثل هذه الطرق التصنيعية فيما يلي:

التصنيع المنزلي: غالبا ما يقوم صغار المنتجين بتصنيع الألبان بدلا من بيعها في صورتها الخام وذلك

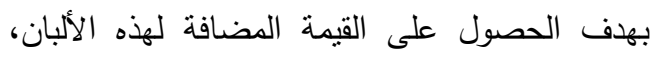

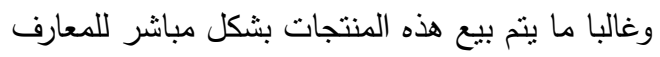
داخل القري أو المدن والمناطق المحيطة بهؤلاء

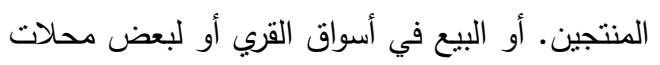

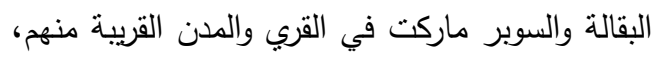

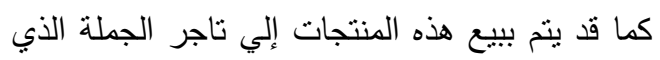

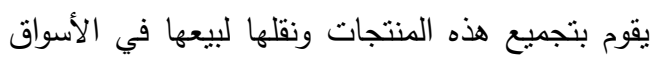
المركزية للقري وللمحافظات أو نقلها لبيعها في المدن لهن الكبرى، هذا وتتم جميع المعاملات المادية بين صغار المنتجين والمتعاملين معهم باختلاف انواعهم بشكل

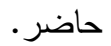
التصنيع في معامل الألبان: تحصل معامل الألبان

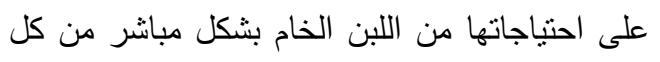




\section{An Analysis Study of Dairy and Dairy Products Supply Chain}

مجموعنين تضم الأولي الأنشطة الفنية والمادية المساندة والتي تشتمل على كل من الخدمات البيطرية والخاصة الاصنة بتوفير الرعاية البيطرية والإرشاد البيطري والانتاجي

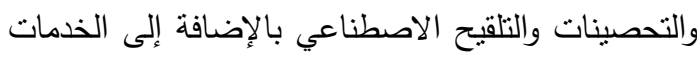

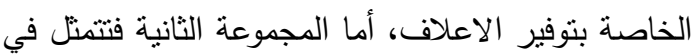
الخدمات المالية الخاصة بتوفير التمويل وخدمات التامين ضد المخاطر • وفيما يلي استعراض لواقع هذه الخدمات

المساندة الفنية والمادية والمالية.

\section{الخدمات الفنية وإلماية المساندة}

الرعاية البيطرية: تعد الهيئة العامة للخدمات البيطرية هي

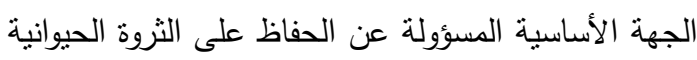

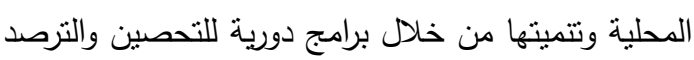

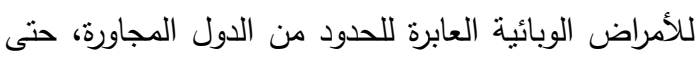

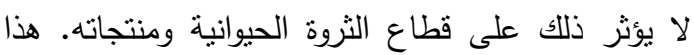
وتقدم الهيئة العامة للخدمات البيطرية خدماتها بالمحافظات الترات والمراكز والقري التابعة لها من خلال الادارات والوحدات

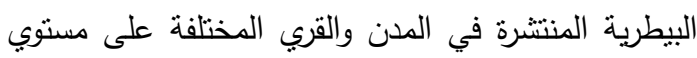

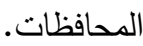

وقد بلغ عدد الادارات البيطرية على مستوي الجمهورية 259 إدارة بيطرية تضم هذه الادارات حوالي 1709 وحد الادرات البطرية بيطرية في متوسط الفترة (2012-2014) موزعة بثكل متفاوت على مستوي محافظات الجمهورية، حيث بلغ عدد الادارات البيطرية في كل من محافظات الوجه البحري

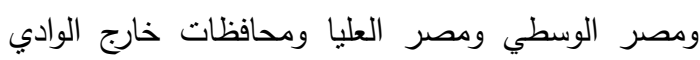
حوالي 136، 42، 46، 351، 35 ادارة بيطرية تضم هذه الإدارات حوالي 988، 331، 306، 84 32 84 وحدة بيطرية، على الترتيب. وقد قدر منوسط عدد القري الرئيسية التابعة 306

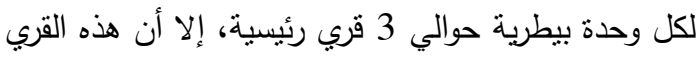
الرئيسية غالبا ما يتبعها عدد من التجمعات الريفية

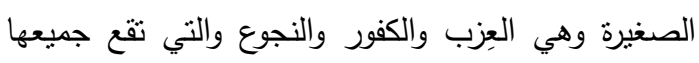
في النطاق المحدد للخدمات التي تقدمها الوحدات

كما قدر متوسط عدد رؤوس الماشية التابعة لكل وحدة

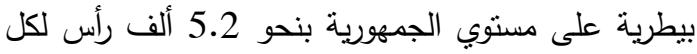
وحدة بيطرية. وتتفاوت قيمة هذا المتوسط بين المحافظات
إعطاء القروض لأصحاب المزارع أو ضمان المزارع

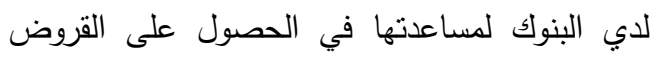

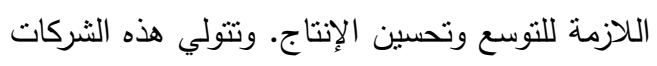

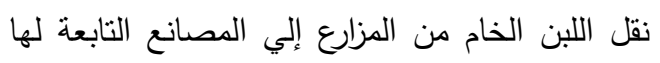

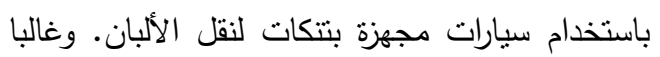
ما يتم اجراء الحسابات المالية بشكل آجل أسبوعيا مع لالبان

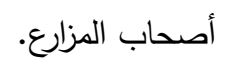
هذا وغالبا ما يزداد حجم اللبن المورد للمصانع في الثتاء ويتناقص في الصيف ويتم تعويض النقص والعجز في الألبان الموردة في هذه الفترات من خلادل استخدام

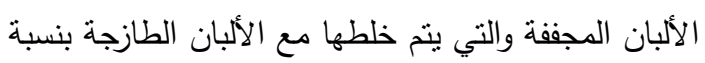

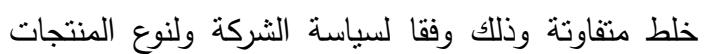

المصنعة.

\section{مرحلة التوزيع ومرحلة الاستهلاك}

ينتم خلال هذه المرحلة نقل وتوصيل الألبان ومنتجاتها المصنعة الي المستهلك النهائي، وقد تتضمن هذه المرحلة خطوة واحدة أو عدد من الخطوات وذلك وفقا لنوع المنتج

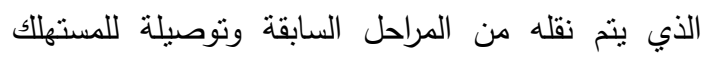
النهائي، وذلك اما من خلال مراكز التوزيع التابعة لثركات

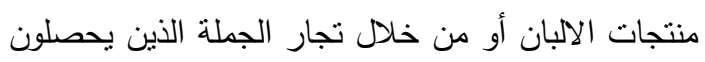
على منتجات الالبان من مصادرها المختلفة ثم القيام بتوصيلها لتجار التجزئة أو المؤسسات الاستهلاكية،

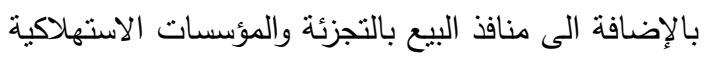

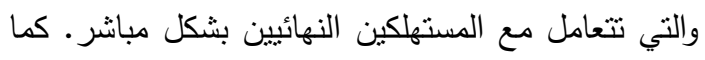
يحصل المستهلكون على احتياجاتهم من الالبان ومنتجاتها من العديد من المصادر والتي تختلف باختلاف طبيعة المنتج النهائي ودرجة تصنيعه.

ثانياً: الخدمات المساندة لسلسلة توريد الالبان

\section{ومنتجاتها}

تعد الجوانب المتعلقة بالمقتصد وما يقدمه من خدمات

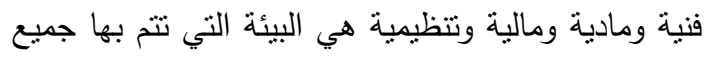
الأنشطة والعمليات على طول سلسلة التوريد. ويمكن تقسيم الخدمات المساندة لسلسلة توريد الالبان ومنتجاتها إلى الى لئل 


\section{S. Ali and Asmaa A. A. Abou-Mosalam}

يقتصر هذا العدد على حوالي 2 طبيب لكل وحدة بيطرية في المنوسط، وعلى ذلك فإن منوسط عدد رؤوس الماشية لكل طبيب بيطري عامل برتفع وبشكل كبير ليقدر بنحو 2.6 ألف رأس من الماشية لكل طبيب علي مستوي الجمهورية، ويختلف هذا العدد بين الاقاليم والمحافظات المختلفة على النحو الوارد بالجدول. ووفقا لذلك بيضح عدم وجود معيار يتم على اساسة تحديد عدد الاطباء

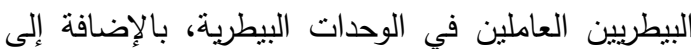
ارتفاع اعداد رؤوس الماثية لكل طبيب بيطري وبلوغ هذه الاعداد اقصاها في محافظات مصر العليا، الامر الذي رؤي

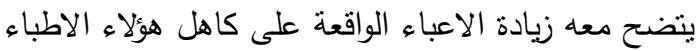
البيطربين والذي ينعكس بدورة على عدم القدرة على تقديم الخدمات البيطرية على النحو الواجب، فضلا عن سوء لبه الخدمات المقدمة لقطاع المربيين.
المختلفة حيث بلغ عدد رؤوس الماشية التابعة لكل وحدة بيطرية في كل من محافظات الوجه البحري ومصر الوسطي ومصر العليا ومحافظات خارج الوادي حوالي 5.3، 4.8، 6.4، 1.4 على الترنيب على النحو المبين بالجدول (1). وتوضتح بيانات الجدول (2) أن متوسط عدد رؤوس الماثية لكل طبيب بيطري على مستوي الجمهورية قد بلغ حوالي 747 رأس من الماشية، كما تبين تفاوت هذا العدد

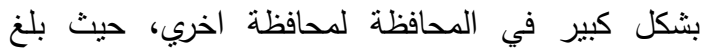
متوسط عدد رؤوس الماثية/طبيب بيطري علي مستوي محافظات الوجه البحري ومصر الوسطي ومصر العليا ومحافظات خارج الوادي حوالي محافظات الوجه البحري حوالي 652، 846، 1160، 354 راس من الماشية. كما تجدر الاشارة إلى أن هذه الاعداد من الاطباء البيطربين لا تمثل الأعداد الفعلية من الاطباء البيطربين

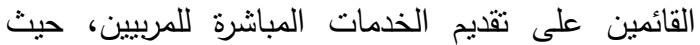

جدول (1): متوسط عدد القري الرئيسة واعداد الماشية لكل وحدة بيطرية في متوسط الفترة (2012-2014)

\begin{tabular}{|c|c|c|c|c|c|c|}
\hline بالألف لكل رؤوس وحدة بيطرية & بالألف رأساد الماشية & عددة القري لكل & الرئيسية القري & 1 عدد الوحدات & البيطرية الإدارات & الأقاليم \\
\hline 5.3 & 5166.0 & 2.7 & 2629 & 981 & 136 & الوجه البحري \\
\hline 4.8 & 1604.7 & 2.8 & 942 & 331 & 42 & مصر الوسطى \\
\hline 6.4 & 1944.6 & 2.7 & 828 & 305 & 46 & مصر العليا \\
\hline 1.4 & 112.5 & 2.6 & 219 & 83 & 35 & خارج الوادي \\
\hline 5.2 & 8827.8 & 2.7 & 4618 & 1701 & 258 & إجمالي \\
\hline
\end{tabular}

المصدر: 1-وزارة الزراعة القطاع الاقتصادي نشرة إحصاءات الثزوة الحيوانية، اعداد متفرقة.

2-20يكيبيديا، الموسوعة الحرة، 14/10/2016.

جدول (2): متوسط أعداد رؤوس الماشية لكل طبيب بيطري في متوسط الفترة (2012-2014)

\begin{tabular}{|c|c|c|c|c|}
\hline عالألف رؤوس الماثلية طبيب & 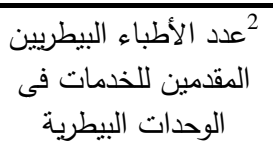 & بالألف رؤوس الماثيبة & بالمدد الأطباء البيطريين & القطاعات \\
\hline 2.6 & 1962 & 0.652 & 7926 & الوجه البحري \\
\hline 2.4 & 663 & 0.846 & 1897 & مصر الوسطى \\
\hline 3.2 & 611 & 1.160 & 1677 & مصر العليا \\
\hline 0.7 & 166 & 0.354 & 318 & خارج الوادي \\
\hline 2.6 & 3401 & 0.747 & 11818 & إجمالي الجمهورية \\
\hline
\end{tabular}


المصدر: 1-الهيئة العامة للخدمات البيطرية، بيانات غبر منشورة.

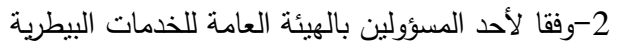

فقط من اجمالي أعداد الرؤوس الحلابة من الجاموس والبالغ عددها نحو 1.6 مليون رأس. هذا وتوضح البيانات الواردة بالجدول انخفاض التناض التقيح

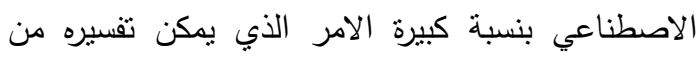

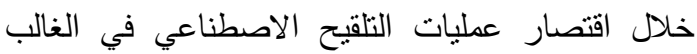

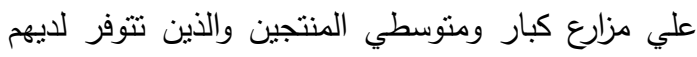

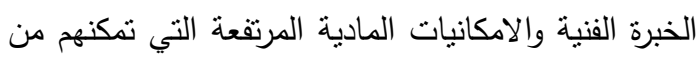

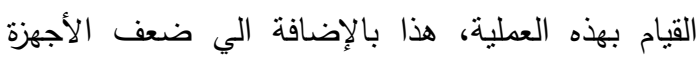

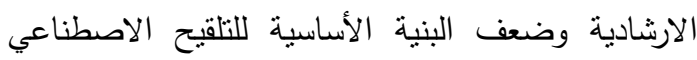

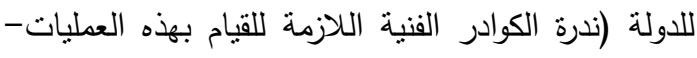
عدم نوافر معامل لإنتاج السائل المنوي المحلي أو لتخزين المستورد منه) وكذللك عد وجود نظام قومي للنسجيل والنسب للتعرف علي الصفات الوراثية للحيوانات.

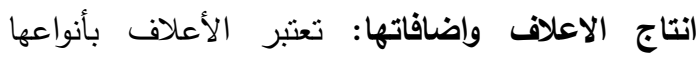

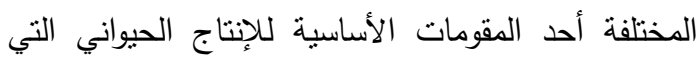

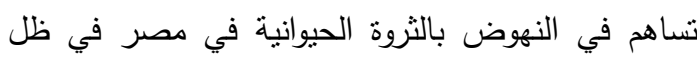

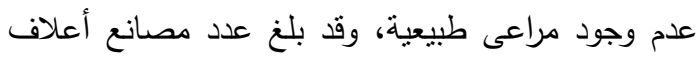
الماشية 195 مصنعاً في منوسط الفترة (2012-2014)

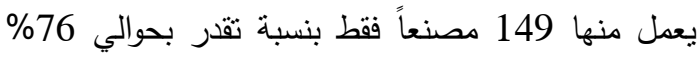
من إجمالي عدد مصانع الأعلاف على النحو الموضح

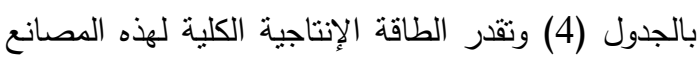

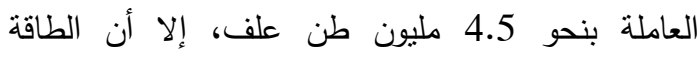
الإنتاجية الفعلية لهذه المصانع تبلغ حوالي 936 ألف طن طن بنسبة تنغيل تقدر بحوالي 20.7\% من إجمالي الطاقة

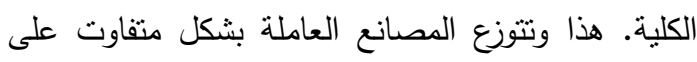

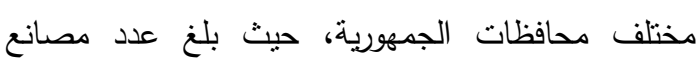
الاعلاف العاملة في محافظات الوجه البحري 92 مصنعاً بنسبة تشغيل تبلغ نحو 19.5\% من الطاقة الإنتاجية الكلية لهذه المصانع. اما محافظات مصر الوسطي فقد بلغ عدد مصانع الاعلاف بها 24 مصنع بنسبة تشغيل

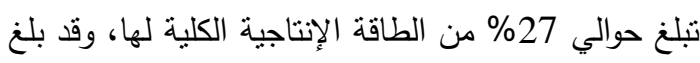

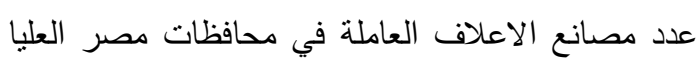

خلمات الارشاد البيطري: تقوم مديريات الطب البيطري من

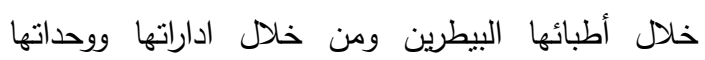
البيطرية المنتشرة في المراكز والقري المختلقة بإجراء

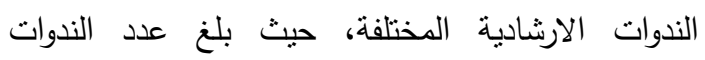

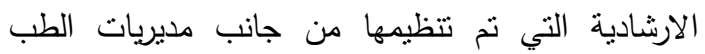

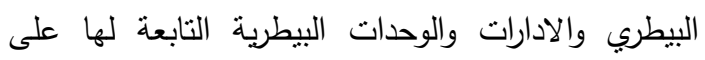
مسنوي محافظات الجمهورية خلال عام 2016 حوالي 16806 ندوة ارشادية موزعة وفقا للدجالات المختلفة3. حيث بلغ عدد الندوات الارشادية في مجال وقاية المانشية

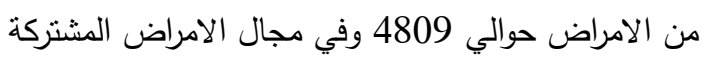
بين الانسان والحيوان حوالي 3627 ندوة، أما الندوات المشتركة فقد بلغ عددها حوالي 2386 ندوة وفي مجال

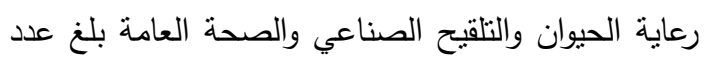

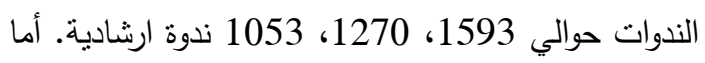
الندوات الخاصة بمجالي التامين علي المانشية والترقيم والتسجيل فتأني بأعداد منخفضة تقدر بحوالي 797،

خدمات التلقيح الاصطناعي: يعد التلقيح الاصطناعي من الطرق الأساسية المستخدمة في عمليات التحسين الوراثي لللثروة الحيوانية والتي تهدف الي تحسين الصفات الإنتاجية

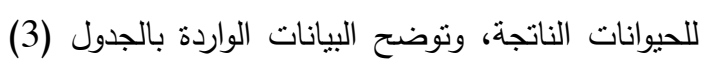

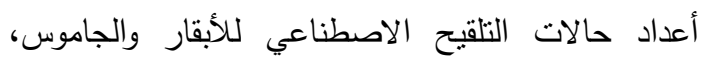

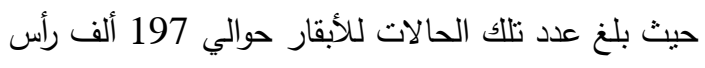
تمثل حوالي 25\% من اجمالي عدد الرؤوس الحلابة من الإندال

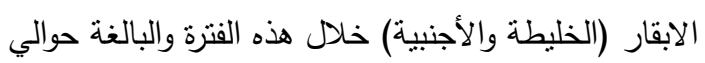

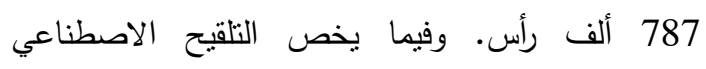
للجاموس فقد انخفضت اعداد رؤوس الجاموس الملقحة اصطناعيا لتقدر بنحو 38 ألف رأس تمثل حوالي 2.3

3- الميئة العامة للخدمات البيطرية، الإدارة العامة للخدمات والإرشاد، بيانات

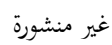




\section{S. Ali and Asmaa A. A. Abou-Mosalam}

الجاهزة، هذا بالإضافة إلى ارتفاع اسعار هذه الاعلاف الجاهزة مقارنة بالخلطات العلفية التي يقوم المنتجين لإهني بتصنيعها داخل مزارعهم لاستخدامها في عملة الانتاج. هذا بالإضافة إلى تعرض هذه المصانع الي عدة مشاكل تتمثل في تقلب اسعار هذه المكونات واحتكار استيرادها من جانب عدد محدود من رجال الاعمال والمستوردين،

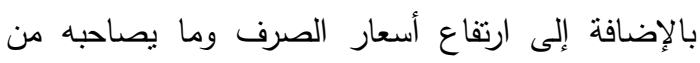
ارتقاع قيمة الواردات وارتفاع أسعار مكونات الاعلاف إقاع

$$
\text { المستوردة. }
$$

24 مصنع بنسبة تشغيل تقدر بنحو 24\% من الطاقة

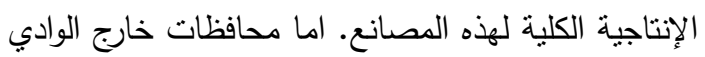
فقد قدر عدد مصانع الاعلاف العاملة بها بحوالي 8 مصانع بنسبة تشغيل تقدر بنحو 30\% . هذا ويمكن تفسير سبب انخفاض نسبة التشغيل لمصانع الاعلاف على مستوي محافظات الجمهورية من خلال انخفاض الطلب على هذه الاعلاف الجاهزة والذي يرجع لعزوف الكثير من منتجين الماشية عن شراء الاعلاف الجاهزة لعدم الثقة في الاعلاف المصنعة

جدول (3): اجمالي أعداد حالات التلقيح الاصطناعي للأبقار والجاموس في متوسط الفترة (2012-2014)

\begin{tabular}{|c|c|c|}
\hline 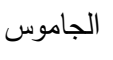 & الابقار & 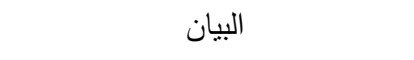 \\
\hline 1611 & 787 & عدد الرؤوس الحلابة 1 (بالألف رأس) \\
\hline 38 & 197 & عدد حالات التلقيح (بالألف رأس) \\
\hline 2.3 & 25.1 & \% حالات التلقيح من الرؤوس الحلابة \\
\hline 15 & 76 & عدد حالات النجاح (بالألف رأس) \\
\hline 40.9 & 38.7 & \% نسبة النجاح \\
\hline
\end{tabular}

المصدر: جمعت وحسبت من وزارة الزراعة القطاع الاقتصادي نشرة إحصاءات الثروة الحيوانية، اعداد متفرقة. 1-عدد الرؤوس الحلابة تمثل عدد الاناث من الابقار والجاموس التي يزيد عمرها عن سنتين

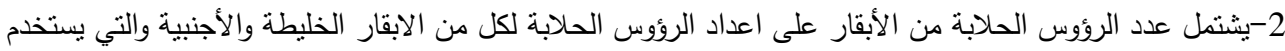
معها تقنية التلقيح الاصطناعي.

جدول (4): الطاقات الكلية والفعلية والمعطلة لمصانع أعلاف الماشية في متوسط الفترة (2012-2014)

\begin{tabular}{|c|c|c|c|c|c|c|c|c|}
\hline (بالألف طن) & & & & & & \multicolumn{3}{|c|}{ الطاقة الإنتاجية } \\
\hline \multicolumn{5}{|c|}{ المصانع العاملة } & \multicolumn{2}{|c|}{ المصانع الغير عاملة } & \multirow{2}{*}{ المدالي } & \multirow[b]{2}{*}{ 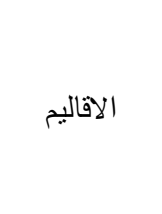 } \\
\hline نسبة التشغيل & الطعاقة & الفلية & الكلية & العدد & الكلية & 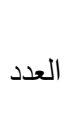 & & \\
\hline 19.5 & 2986.3 & 721.8 & 3708.1 & 92.3 & 470.5 & 26 & 118.3 & الوجه البحري \\
\hline 26.9 & 223.9 & 82.6 & 306.5 & 24.3 & 53.4 & 7.7 & 32 & مصر الوسطي \\
\hline 23.9 & 291.2 & 91.4 & 382.7 & 24 & 14.5 & 5 & 29 & مصر العليا \\
\hline 30.3 & 91.7 & 39.8 & 131.6 & 8.0 & 171.8 & 7.3 & 15.3 & خارج الوادي \\
\hline
\end{tabular}




\begin{tabular}{l|l|l|l|l|l|l|l|l}
\hline 20.7 & 3593.2 & 935.6 & 4528.8 & 148.7 & 710.2 & 46.0 & 194.7 & إجمالي الجمهورية \\
\hline
\end{tabular}

المصدر: جمعت وحسبت من وزارة الزراعة القطاع الاقتصادي نشرة إحصاءات الثروة الحيوانية، اعداد متفرقة.

علي مستوي الجمهورية، هذا ويتوزع التأمين علي بنسب متفاوتة بين محافظات الجمهورية، حيث تبلغ نسبة التأمين عليها في محافظات الوجه البحري 45\% اما محافظات

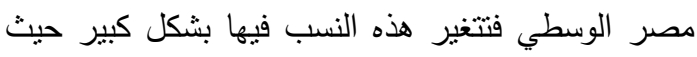
تبلغ 14\% وذلك من اجمالي الرؤوس المؤمن عليها علي لـوني مستوي الجمهورية، وفي محافظات مصر العليا لتصل نسبة التأمين علي الرؤوس الحلابة حوالي 24\% وفئمات ونتخفض

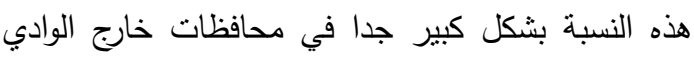

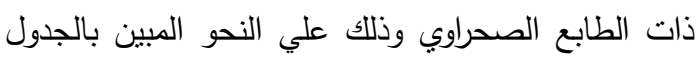

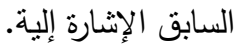

خدمات الايتمان والتمويل الموجه لقطاع الثروة الحيوانية: تظهر أهمية الاتثمان الزراعي في توفير التمويل اللازم لتتمية وتحديث قطاع الثروة الحيوانية، ويعد بنك التتمية والايتمان الزراعي أهم المؤسسات التمويلية للنشاط الزراعي لتروائه في مصر من خلال فروعة التي تصل إلى 1210 فرع وبنك قرية تغطى كافة المحافظات المصرية، ويعمل البنك على تقديم التمويل للقطاع الزراعي في شتى مجلى مجالاته للنهوض بالقطاع ورفع جدارته الإنتاجية، وذلك من خلال تقديم كل من القروض قصيرة ومتوسطة الاجل وطويلة الاجل، وتمثل قروض الثروة الحيوانية جانبا كبيرا من محفظة القروض التي يمنحها البنك.
الخدمات المالية المساندة

خدمات التأمين على الماثية: يعد قطاع الثروة الحيوانية من أكثر القطاعات عرضة للمخاطر والتقلبات والخسائر نتيجة لتأثره بالعوامل والظروف الجوية وانتشار الأمراض

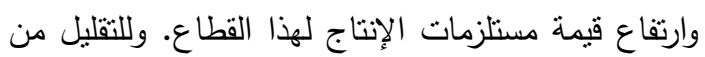
المعاناة التي يتعرض لها هذا القطاع نثأت فكرة الثأمين

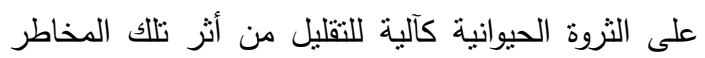
وتعويض المربين حال تعرض حيواناتهم لأي نوع من لئن

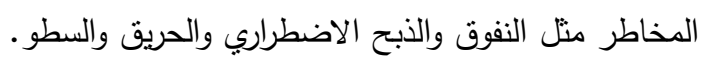
وغير ذلك من المخاطر، حيث ينم ذلك ضمن مجموعة من الإجراءات الفنية والإدارية والمالية المحددة من قبل صندوق التأمين على الماشية. وتوضح البيانات الواردة بالجدول (5) نسبة الابقار والجاموس المؤمن عليها من اجمالي اعداد الابقار والجاموس في مصر خلال عام

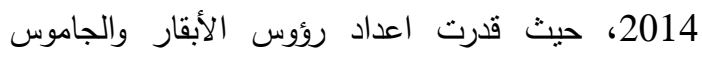
المؤمن عليها بحوالي 852.5 ألف رأس مقارنة بالأعداد الاد والهار الاجمالية من الابقار والجاموس والبالغة حوالي 8.7 مليون رأس، الامر الذي يتضح معه الانخفاض الثنديد في اعداد

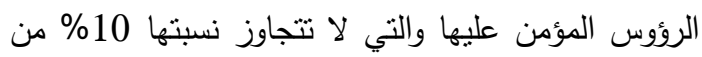

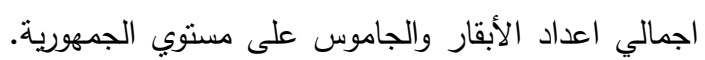
كما بلغت نسبة التامين علي الرؤوس الحلابة حوالي التياز 34 من اجمالي رؤوس الابقار والجاموس المؤمن عليها

جدول (5): نسبة الابقار والجاموس والروئوس الحلابة المؤمن عليها من اجمالي اعداد الابقار والجاموس لعام 2014

\begin{tabular}{|c|c|c|c|c|c|}
\hline المؤمن علية & عدد الرؤوس & $\begin{array}{c}\text { المؤمن عليها من الابقار والجاموس } \\
\text { الاجمالي }\end{array}$ & أعداد الابقار والجاموس عليها بالرأس & اجمالي اعداد الأبقار & المحافظات \\
\hline 45 & 285264 & 9.9 & 496835 & 5029508 & الوجه البحري \\
\hline 14 & 18953 & 6.6 & 110024 & 1675243 & مصر الوسطى \\
\hline 24 & 80382 & 12.7 & 238982 & 1885024 & مصر العليا \\
\hline
\end{tabular}




\begin{tabular}{c|c|c|c|c|c}
\hline 8 & 1430 & 5.5 & 6685 & 121978 & خارج الوادئ \\
\hline 34 & 386029 & 9.8 & 852526 & 8711753 & إجمالي الجمهورية \\
\hline
\end{tabular}

المصدر: جمعت وحسبت من وزارة الزراعة القطاع الاقتصادي نثرة إحصاءات الثروة الحيوانية، اعداد متفرقة

لمحافظات مصر العليا بحوالي 77.3\% من اجمالي القروض الزراعية قصيرة الاجل المقدمة لهذه المحافظات.

القروض متوسطة الاجل: تنتل نسبة القروض منوسطة

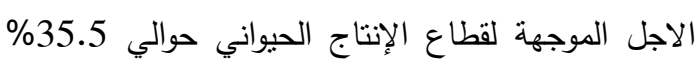
من اجمالي قيمة القروض الزراعية متوسطة الاجل خلال

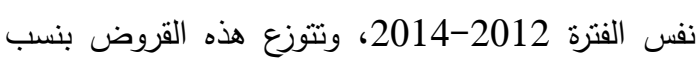

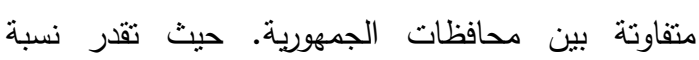

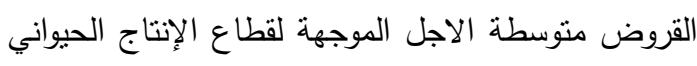

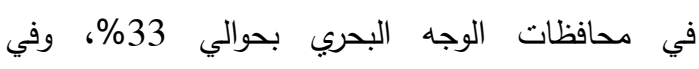

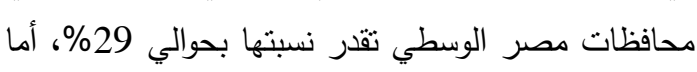
محافظات مصر العليا فتقدر نسبة قروض الثروة الحيوانية

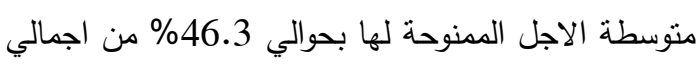

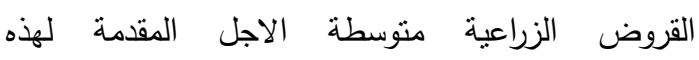

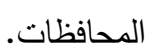

القروض قصيرة الاجل: توضح البيانات الواردة بالجدول (6) قيمة القروض قصبرة الاجل التي قدمها بنك التتمية الاجية

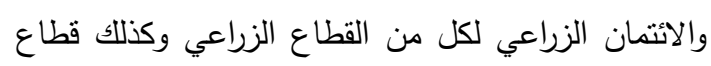

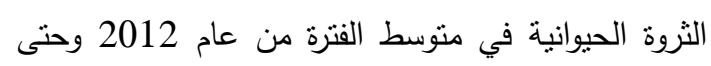
عام 2014. حيث تقدر نسبة القروض قصيرة الاجل الموجهة لقطاع الإنتاج الحيواني بحوالي 59.2 اجمالي قيمة القروض الزراعية قصيرة الاجل خلا الفتل الفترة

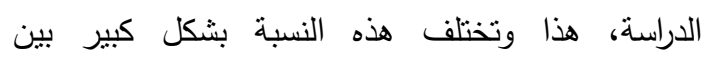
محافظات الجمهورية. حيث تقدر نسبة القروض قصيرة

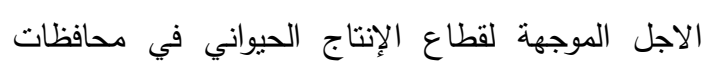

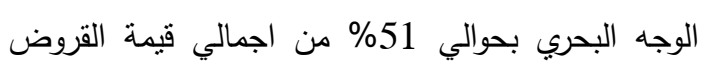

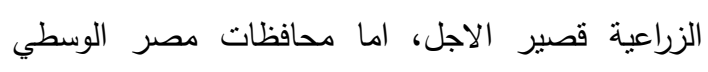

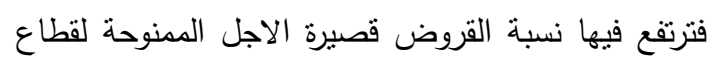
الثروة الحيوانية مقارنة بنسبة القروض الزراعية قصبرة الاجل الممنوحة لهذه المحافظات لتصل إلى 80.2\%

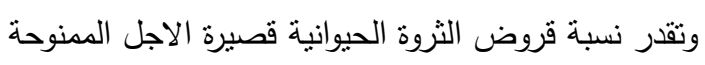

جدول (6): القروض والسلف الاستثمارية قصيرة ومتوسطة الاجل المقدمة من بنك التنمية والائتمان الزراعي للقطاع

\begin{tabular}{|c|c|c|c|c|c|c|}
\hline \multicolumn{3}{|c|}{ القروض متوسطة الاجل بالمليون جنيه } & \multicolumn{3}{|c|}{ القروض قصيرة الاجل بالمليون جنيه } & \multirow{2}{*}{ 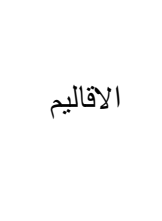 } \\
\hline$\%$ & قروض الانتاج & إجمالي القروض & $\%$ & قروض الانتاج & إجمالي القروض & \\
\hline 33.0 & 440.5 & 1336.6 & 51.0 & 1896.7 & 3719.3 & الوجه البحري \\
\hline 28.8 & 139.0 & 482.6 & 80.2 & 805.5 & 1004.7 & مصر الوسطى \\
\hline 46.3 & 283.0 & 611.1 & 77.3 & 413.0 & 534.6 & مصر العليا \\
\hline 18.2 & 0.62 & 3.4 & 1.0 & 0.0 & 0.8 & خارج الوادي \\
\hline
\end{tabular}




\section{An Analysis Study of Dairy and Dairy Products Supply Chain}

\begin{tabular}{l|l|l|l|l|l|l}
\hline 35.5 & 863.1 & 2433.7 & 59.2 & 3115.3 & 5259.4 & إجمالي الجمهورية \\
\hline
\end{tabular}

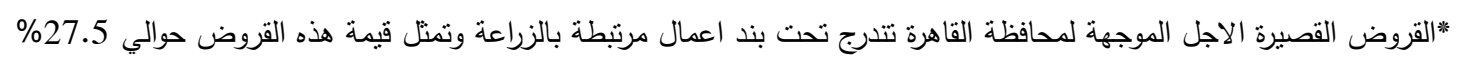

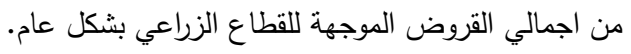
المصدر: جمعت وحسبت من الجهاز المركزي للتعبئة العامة والاحصاء، الكتاب الاحصائي السنوي، باب الزراعة، اعداد متفرقة.

على طول سلسلة التوريد، فضلا عن القيام بتحليل البيانات والمعلومات ذات الصلة بالقطاع والخاصة بالخدمات المادية والفنية والمالية المقدمة لهذا القطاع، بالإضافة الي استطلاع آراء بعض المختصين في المجالات المختلفة المرتبطة بالقطاع. وبناءً على ما تم تجميعه من بيانات ومعلومات

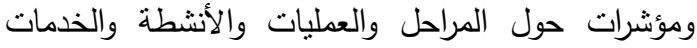

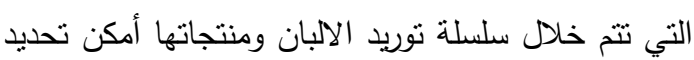

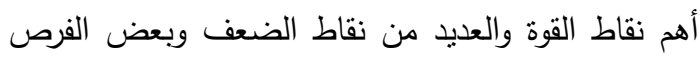
والتهديدات التي نواجه هذا القطاع.

نقاط القوة: تمثلت أهم نقاط القوة في قطاع الالبان ومنتجاتها فيما يلي: 1. توافر العديد من السلالات المستخدمة في انتاج اللبن.

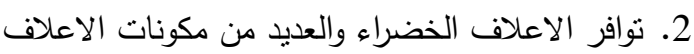

$$
\text { الجافة على مدار السنة. }
$$

3. توافر الخدمات البيطرية والارشادية من جانب كل من الفن الفاءه

$$
\text { القطاع العام والخاص. }
$$

4. اتجاه العديد من المنتجين لتبني الأساليب التكنولوجية

$$
\text { الحديثة }
$$

5. وجود صندوق للتامين على المانشية

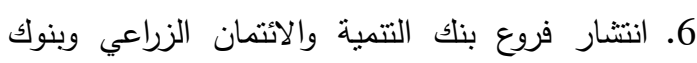
القري في غالبية قري ومراكز المحافظات. 7. وجود العديد من المعامل البلدية والثركات الحديثة في

$$
\text { مجال صناعة الألبان ومنتجاتها }
$$

8. زيادة الوعي لدي السكان بأهمية الألبان ومنتجاتها

$$
\text { وقيمتها الغذائية وتتوع الطلب عليها. }
$$

ثالثاً: التحليل البيئي الرياعي لسلسة توريا

\section{الالبان ومنتجاتها}

يعاني قطاع انتاج الالبان من العديد من الشكلات

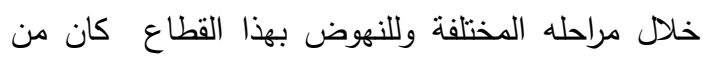

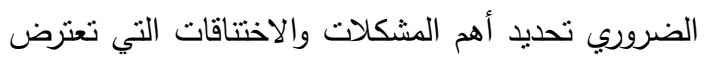
أداء العمليات والأنشطة والمراحل المختلفة لسلسة توريد الالبان ومنتجاتها والتي تحد من كفاءة أداء العمليات المختلفة، ومن ثم تحديد نقاط الضعف التي يعاني منها

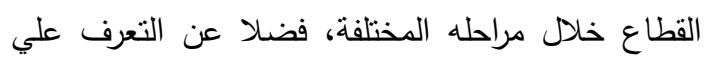

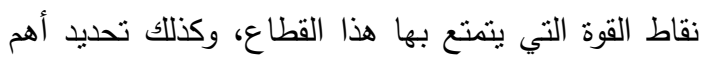

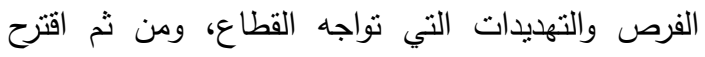
بعض الإجراءات والحلول التي من شأنها تعزيز نقاط القوة والحد من نقاط الضعف والاستفادة من الفرص المتاحة والتقليل من أثر التهديدات.

ويعد التحليل البيئي الرباعي أسلوب تحليلي يتم من خلاله تحديد وتحليل وتقييم العوامل والمتغيرات التي تؤثر علي أداء القطاع، ويمتد هذا التحليل ليشمل تحليل البيئة الداخلية للمؤسسة وما تتضمن علية من نقاط القوة والضعف، وتحليل البيئة الخارجية للمؤسسة وما تشتصله من فرص وتهديدات، حيث تعد كلمة SWOT اختصار

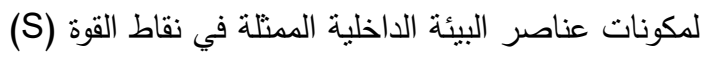
Weaknesses (W) ونقاط الضعف Strengths وكذلك عناصر البيئة الخارجية المتمنلة في الفرص (W) ، Threats (T) والتهديدات Opportunities واعتمدت الدراسة في تحليل البيئة الداخلية والبيئة

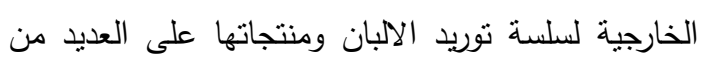

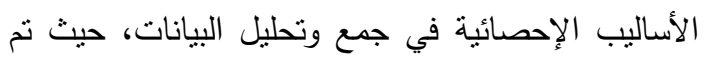
القيام بتجميع استمارات استيان من العديد من الفاعلين 
11.انخفاض مسنويات الأجور الحقيقية للقاعدة العريضة من السكان الامر الذي يقلل من الطلب على الالبان

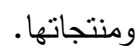

الفرص: تمنلت الفرص المتاحة امام هذا القطاع في كل

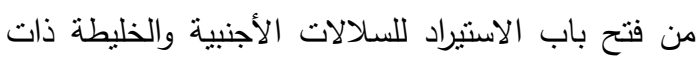
الإمكانيات الإنتاجية العالية، وزيادة اعداد السكان ومن ثم

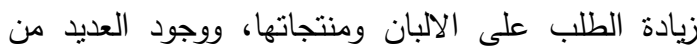

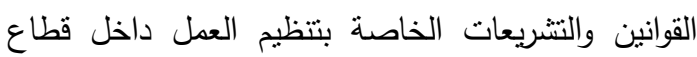
الإنتاج الحيواني بمصر ، فضلا عن وجود أسواق تصديرية

$$
\text { لبعض منتجات الالبان للأسواق الخارجية. }
$$

التهايدات: تمنلت أهم التهديدات في ارتفاع سعر الصرف وما يصاحبه من ارتفاع أسعار المستلزمات الإتتاجية

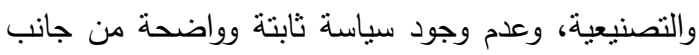
الدولة في عمليات الاستيراد للمنتجات الحيوانية

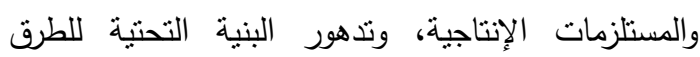
والمنشآت الإنتاجية والخدمية المرتبطة بقطاع الإنتاج

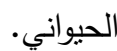

السياسات والحلول المقترحة للنهوض بقطاع انتاج الالبان: انتهت الدراسة بوضع مجموعة من السياسات

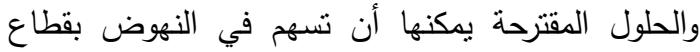
انتاج الالبان ولعل من أهمها: 1. إعادة هيكلة الجمعيات التعاونية واتحادات المنتجين للقيام بتوفير القروض الميسرة ومستلزمات الإنتاج لصغار المنتجين بأسعار مخفضة نسبياً. 2. نوفير نظام معلومات وقاعدة بيانات عن السلالات الحيوانية من حيث أعدادها وانواعها وانتاجيتها واماكن

$$
\text { انتشارها. }
$$

3. تطوير البنية التحتية لأسواق الماشية، وتنظيم اللوائح

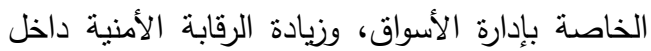

$$
\text { الأسواق. }
$$

4. التوسع في زراعة الأصناف عالية الإنتاجية من محاصيل الاعلاف الخضراء والعطل على استتباط سلالات عالية الإنتاجية ومقاومة للأمراض والآفات.
نقاط الضعف: تعددت نقاط الضعف والمشاكل والاختتاقات التي تواجه المراحل المختلفة لسلاسل توريد الألبان ومنتجاتها وتمنلت أهم نقاط الضعف في كل من

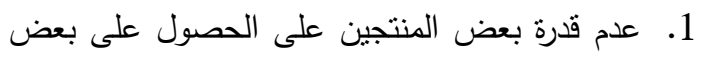

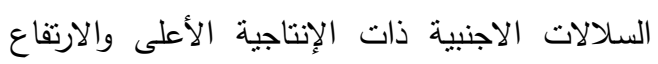
المطرد لأسعار حيوانات اللبن.

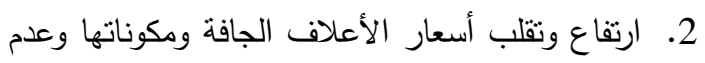
النقة في جودة الاعلاف الجاهزة

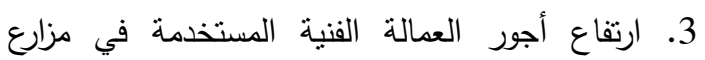
الإنتاج الحيواني 4. ضعف أداء الخدمات البيطرية المقدمة من جانب الباتب القطاع الحكومي وارتفاع تكلفة التحصينات الخاصة والطبيب البيطري الخاص

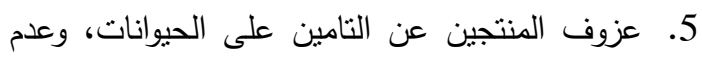

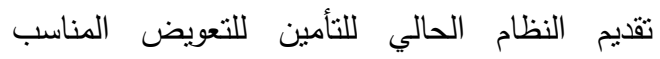
لللمنتجين في حالة تعرض بعض الحيوانات للنفوق

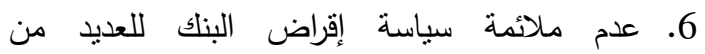
مشروعات الإنتاج الحيواني 7. ضعف البنية الأساسية لمجمعي الالبان واستخدام الأساليب البدائية التقليدية في القيام بعمليات تجميع لالئي الأليان الألبان ونقلها، وانعدام الرقابة على مجمعي الالبان وعمل الكثبر منهم بدون أي نراخيص. 8. ارتفاع تكلفة مستلزمات الإنتاج المستخدمة في العملية التصنيعية للألبان واحتكار قلة من تجار الجملة لتجارة

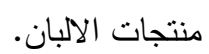
9. تعرض معامل ومصانع منتجات الألبان للعديد من

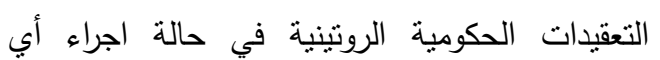
توسعات او استخراج تراخيص جديدة

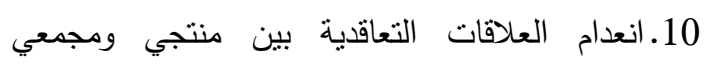

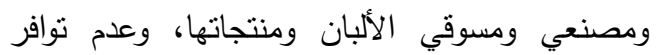
وسائل مناسبة لنقل الالبان ومنتجاتها خلال المراحل المختلفة، وضعف البنية الأساسية للعديد من منافذ

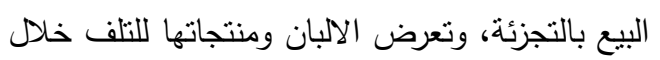
عمليات النقل والتخزين. 
الحديثة في نوفير منتجات الألبان بمواصفات آمنة

علي صحة المستهلكين.

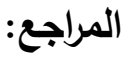

1. حانت عبد العليم إيراهيم شاهين، دراسة اقتصادية

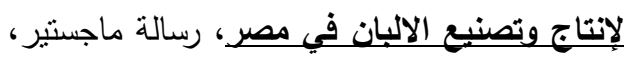

قسم الاقتصاد الزراعي، كلية الزراعة، جامعة عين

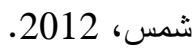

2. دعاء سمير محمد مرسي أحمد، التقييم الاقتصادي

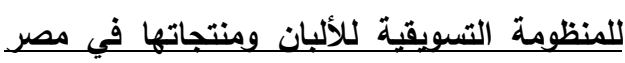

وإمكانية تطويرها، رسالة ماجستير، قسم الاقتصاد

الزراعي، كلية الزراعة، جامعة عين شمس، 2008.

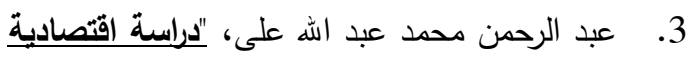

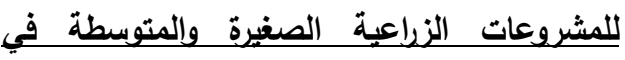

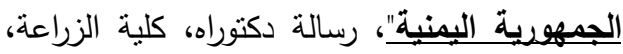

جامعة المنوفية 2014.

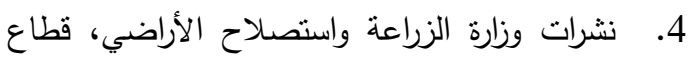

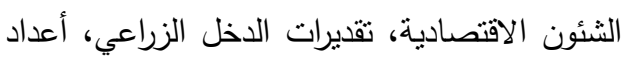

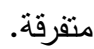

5. نشرات وزارة الزراعة واستصلاح الأراضي، قطاع

الثئون الاقتصادية، إحصاءات الثروة الحيوانية،

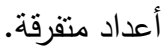

6. الجهاز المركزي للتعبئة العامة والاحصاء، النشرة

السنوية لنقديرات الدخل من القطاع الزراعي، أعداد

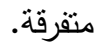

7. الجهاز المركزي للتعبئة العامة والاحصاء، الكتاب

الاحصائي السنوي، باب الزراعة، أعداد متفرقة.

8. Anjani Kumar, Milk Marketing Chains in Bihar: Implications for Dairy Farmers and Traders, Agricultural Economics Research Review, Vol. 23 (Conference Number) 2010 pp 469-477.

9. LACTIMED, Promoting Mediterranean Dairy Products, Developing the typical dairy products of Alexandria and Beheira Diagnosis and local strategy, March 2014.

10. R. Trevor Wilson, The Red Meat Value Chain in Tanzania, A report from The
5. التوسع في استخدام الاعلاف غير التقليدية المعتمدة على المخلفات الزراعية. 6. وضع خطة شاملة لرفع كفاءة أداء الخدمات البيطرية والإرشاد البيطري. 7. وضع اليات وسياسات لتحفز المنتجين على التامين على مانشيتهم مع تقديم التعويضات المناسبة للمنتجين

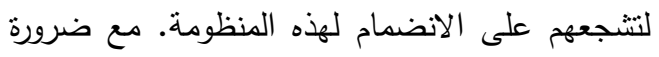

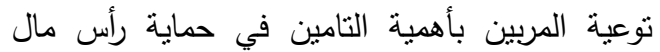
المربي من خلال حماية الحيوانات المؤمن عليها. 8. تعديل سياسات بنك التتمية والائتمان الزراعي بما لتانيا يتتاسب مع طبيعة انشطة الإنتاج الحيواني، والبحث

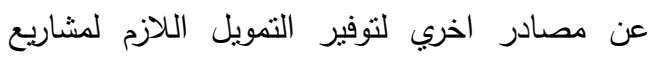
الإنتاج الحيواني.

9. تتظيم عمل مجمعين الألبان ووضع اليات تمكن من تفعيل الرقابة على هذه الفئة.

10. تشجيع نكوين اتحادات لمصنعي منتجات الألبان وتعاونها مع خطوط الاثتمان المناسبة لتوفير

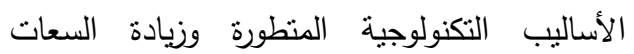
الإنتاجية لمعامل الألبان، وزيادة قدراتها التساوميه. 11. تفعيل دور الارشاد الإنتاجي لتدريب المنتجين على الإنى استخدام الأساليب التكنولوجية الحديثة في الإنتاج وإعادة تأهيل وتدريب عمال معامل ومصانع الألبان. 12. توحيد الجهات الرقابية ذات الصلة بمنح تراخيص

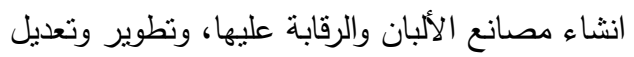
القوانين والتشريعات لمواجهة المشكلات التي نواجه

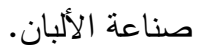
13. قيام التعاونيات الاستهلاكية بتحسين مستويات الطلب على منتجات الألبان وذلك من خلال قيامها

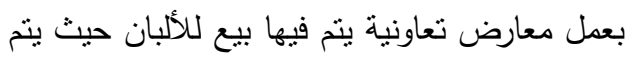
شراء هذه المنتجات بكميات كبيرة من مصادرها ثم توزيعها بهامش ربح وأسعار مخفضة تزيد من الطلب عليها. 14. القيام بحملات توعية للمستهلكين من خلال الوسائل الإعلامية المختلفة لتوعيته بدور الصناعات 


\title{
AN ANALYSIS STUDY OF DAIRY AND DAIRY PRODUCTS SUPPLY CHAIN
}

\author{
I. S. Ali and Asmaa A. A. Abou-Mosalam \\ Department of Agricultural Economics, Faculty of Agriculture, Menufiya University
}

\begin{abstract}
Livestock is one of the main pillars of agricultural production in Egypt. It is not only a source of agricultural economic growth, it is also an important factor in the economic and social stability of a large number of the agricultural population and other workers in the livestock production and food industries associated with this sector. The livestock sector faces a major challenge to increase the productivity of animal units of dairy and meat in light of the many technical, financial, economic and marketing obstacles facing this sector,

It has been possible to analyze the supply chain of animal food products and keep track of these products during the various stages of identifying the most important weaknesses, problems and obstacles facing this sector, which limit the performance of the various processes and functions required during these stages of efficient represented by: High and volatile prices of services and supplies of production and manufacturing, Weak integrative relationships and lack of contractual relations at all stages and levels of the supply chain. Weak infrastructure and service for the majority of marketing and manufacturing operations, Weak performance of services and government control at different stages of these products, The scarcity of trained technical personnel, the high wages of labor, and the low purchasing power of consumers in local markets.

Some policies and solutions have been proposed to promote this sector. The most important of these was: The restructuring the cooperative societies of producers, manufacturers and credit lines and restoring their role in supporting all production requirements and providing the necessary funding for the adoption of advanced technological methods at all stages and activities along the supply chain, work on developing the infrastructure and organization of government service facilities operating in the sector and improve the efficiency of its performance while providing appropriate data bases on this sector, Activating and tightening the governmental control over all facilities and establishments operating in the sector, and working to sensitize all actors along the chain to all their rights and responsibilities during their dealings with all the parties involved in this series.
\end{abstract}

Key words: Swot Analysis, supply chains, Strengths, Weaknesses, Opportunities, Threats, Dairy Products 